\title{
CHALLENGES OF DIGITALIZATION AND E-PROCUREMENT SYSTEMS IN THE PROCUREMENT FIELD IN THE CASE OF GENPACT
}

\author{
Maria Alexandra MAASSEN ${ }^{a^{*}}$ \\ ${ }^{a}$ Bucharest University of Economic Studies, Romania
}

DOI: $10.24818 / \mathrm{IMC} / 2020 / 03.03$

\begin{abstract}
Digitalization has become a main source of potential for applications, facilitating more efficient and more cost effective work practices worldwide. While this trend of digitalization has impacted most areas of activity globally, the dynamics of companies, processes and organizational structures in terms of change management challenges have also evolved generally towards less decentralized operating systems, less hierarchical levels, more automated processes and more cooperation between organizational members. However, it has also brought numerous challenges within the business field especially, where smart applications and cloud IT systems involve more stakeholders of the process, who need to interact on a daily basis in terms of process achievement.

The present paper presents some of the main advantages, but also some of the main issues in terms of organizational change management on the procurement level at Genpact Romania for the years 2015-2019. The research focuses on the company's new Procure-to-Pay software system, Coupa Ebuy, that brought tremendous advantages in terms of time and costs decreasing for purchase order management, as well as an efficient system of order management issuance and checking, but also challenges within the organization and a new approach to suppliers, buyers and other involves parties in the process for the mentioned period.

The paper presents a practical overview of the implementation of the new technological tool for supporting the procurement process within the company, that impacted the organizational change management and the process changes as an adapting strategy to the automation trend within the firm.
\end{abstract}

KEYWORDS: procurement, change management, negotiation, $P 2 P$, strategic management

\section{INTRODUCTION}

Today the procurement function is not only a backup office function to support other departments, but a field itself, that requires continuous innovation and digitalization in order to become competitive. Through digitalization, namely e-procurement systems, a network between buyers, suppliers, users and other stakeholders of the procurement process within one or more organizations is created and maintained. Nowadays as companies go international there is an increased need for eprocurement systems in order to maintain control over operations, maintain relationship between buyers and suppliers and reduce costs. Some studies have shown e-procurement technology in procurement makes is possible for firms to lower total purchase costs on average by $8-12 \%$ (Piera et al., 2014).

In the B2B process especially the e-procurement systems can ensure the networking of buyers, sellers and users of the purchased goods, which can help with the control, measurement and evaluation of the procurement operations. There are more levels of procurement, namely strategic,

\footnotetext{
*Corresponding author. E-mail: maria_nichifor@hotmail.com
} 
tactical and operational procurement, of which the strategic procurement typically is responsible for strategic activities, such as appointing suppliers and contracts to suppliers, which are further used in tactical and operational procurement (Mahdillou \& Akbari, 2014). Thus, strategic procurement offers the basis in terms of accepted and preferred suppliers and the general contracts, which can be further used by tactical and operational employees in daily activities (Van Weele, 1994). A trend nowadays is the e-procurement, which is practically 'an information technology-based procuring system that lies at the input end of the supply chain”' (Presutti, 2003). Lederer et. al (2001) emphasized that a company can use e-procurement as a strategic tool to gain strategic advantages through more business efficiency and more access to information.

E-procurement has become a main way to do procurement at all levels and ensure the networking between strategic, tactical and operational procurement, as well as with suppliers and end customers. Some benefits of e-procurement besides this networking are also a better administration of information through all areas of procurement, cost and time savings for organizations and employees, reducing paperwork and other such advantages (Sitar, 2011).

However, e-procurement technology also brings challenges with organizational and process changes and the need to integrate all levels of procurement, strategic, tactical and operational in order to ensure a smooth flow of orders, communication and processing of end-customers' needs.

The present paper has the objective to analyze the effects of digitalization and e-procurement systems change from Ariba to Ebuy Coupa for Genpact in Romania in terms of process changes and organizational changes. The advantages and challenges of introducing the new e-procurement system Ebuy Coupa are analyzed and emphasize the main changes within the department responsible for processing the procurement activities for a pharmaceutical company.

\section{LITERATURE REVIEW}

Procurement and management of material resources can be defined as a set of interdependent, logically linked and value added sub-processes, which takes place within the organization in order to ensure and manage the elements necessary to conduct business in an efficient and effective manner (Cârstea et al., 2014; Presutti, 2003). Procurement quality can be obtained through the following: value engineering, variety reduction, standardization and specifications, as shown in Figure 1 . These tools can be used to contribute to a better financial performance in procurement. In the project management of procurement several factors are important, but selecting the right supplier is one of the most challenging and can require a considerable amount of effort (Buzzetto et al., 2020). Many companies also outsource the procurement function to other companies, that have to work according to the hiring company's standards. Outsourcing of the procurement function can be done to decrease stock levels, improve quality, improve the integration of supplier and purchase systems and to add for a successful cooperation (Hila \& Dumitrascu, 2014). Outsourcing the procurement function also implies a certain risk as the information and a part of the process is trusted to the subcontractor, however it can bring cost savings, as for example in other regions the employees costs are lower or the process itself. Regarding the buyer-seller relationship or the relationship between the buyer and the supplier, a collaborative relationship is usually wanted in the procurement process with the following characteristics:

- $\quad$ Establishing certain suppliers for each purchased item;

- $\quad$ Establishing long-term agreements and performance targets;

- $\quad$ Sharing advantages and results between partners;

- $\quad$ Common measures and strategies for a better supplier performance;

- $\quad$ Solving conflicts through common measures of the business partners;

- Cooperating together as business partners in case difficulties arise in the cooperation or throughout the process; 
- $\quad$ Striving to obtain high-quality, flawless products according to the necessary standards, that the supplier is able to achieve through their processes (Hila \& Dumitrascu, 2014).



Figure 1. The conceptual model of Procurement quality controls vs. Procurement performance

Source: Munyimi (2019)

There are several levels of procurement, namely: operational, strategic and tactical. As illustrated in Figure 2 the left circle describes the operations adding value in procurement, namely strategic procurement, while the circle on the right describes the operational procurement activities and the oval linking the two is the tactical procurement, which links the strategic and operational procurement. Strategic procurement ensures mainly the suppliers deals and the contracts, which can be further used in tactical and operational procurement activities and ensure efficient cost and performance levels. Tactical procurement should contribute to value drivers, such as price competitiveness and service levels, while the operational procurement has to ensure the goods and services supply to satisfy the end user needs. 


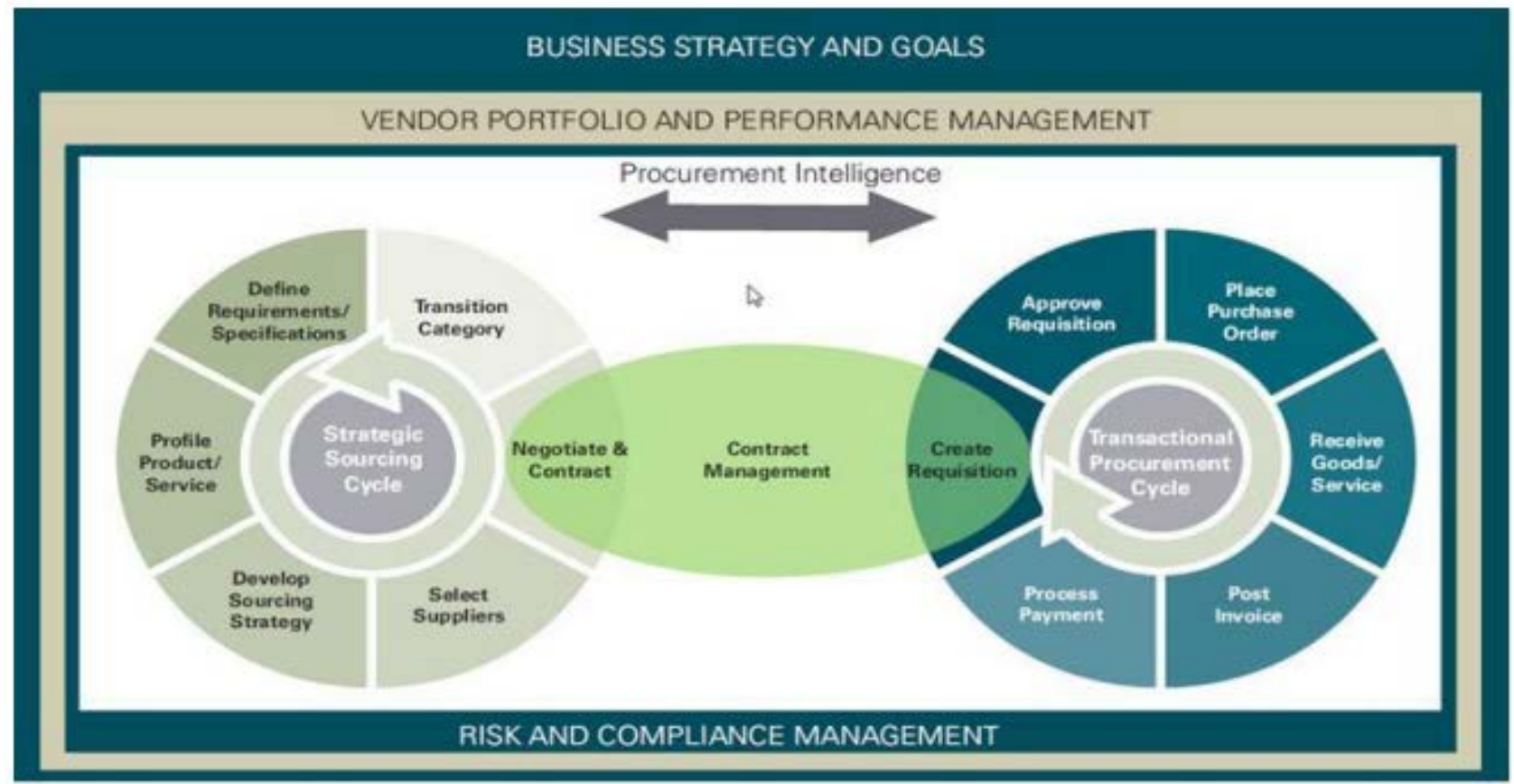

Figure 2. Procurement interlinked processes

Source: Ravi (2012)

As digitalization has become an imperative in several fields of activity the procurement process was also digitalized regarding several processes through e-procurement systems. Today e-procurement systems are one of the main methods to do procurement also for companies, as well as for individuals. Morris et al. (2000) define e-procurement as a process based on more steps, respectively from organization's strategy for procurement to the implementation and use of an eprocurement. Another author, Van Weele (1994), described e-procurement as the use of Internet technology in the process of providing goods and services. E-procurement offers several advantages for both sides, namely purchasing agents and buyers, as well as users, such as: lower supplier costs, reduced maverick buying, reduced order error rate, time savings, competitive advantages, the possibility of focusing on more value adding activities, decentralized systems of purchasing, measuring supplier performance and other, but meaning organizational changes and reengineering of processes especially in terms of the B2B procurement process (Piera et al., 2014). The authors describe that with e-procurement the entire procurement process is handled online, so the company purchases different things, from raw materials to services, using B2B systems, while these tools offer companies the possibility to decrease the cost and time of the procurement process, improve inventory and stocks management and, consequently, this is reflected in a decisive improvement in the management of all business processes. As an advantage e-procurement brings the possibility of a more effective management of the entire process of purchasing and supply network for large companies, while for smaller companies the possibility of becoming global with efficient costs. Some examples for companies include Ebuy offered by Coupa and Ariba. The Coupa procurement system offers more benefits to customers, such as an easier shopping process, easier management of the procurement system, while for firms it offers the possibility of directing employees time for more valuable tasks and through more efficiency it also provides more consumer satisfaction (Coupa, 2020). Some disadvantages of e-procurement, that are also a concern within companies using these systems are: the issue of quality measurement of services, which can be difficult to evaluate, security issues and protection of data, high training costs for employees, need of restructuring processes in order to align them to e-procurement systems (Sabri, 2019). 


\section{METHODOLOGY}

The current research analyzes the organizational changes in terms of process, advantages for customers and personnel, as well as challenges in the case of Genpact in Romania with the implementation of Ebuy (Coupa) instead of Ariba. The findings are based on direct observations in the procurement department working for a pharmaceutical company, as I worked between July 2015 and March 2019 and witnessed the whole process throughout the four years of work. The procurement department experienced several organizational and process changes during the implementation process from Ebuy (Coupa) to Ariba from implementation of more catalogues and more catalogue products, more responsability of the end customers for catalogue orders and processing orders operations mainly in Ebuy and not anymore with SAP support in the case of more activities. These have simplified on the one side for purchasing agents, strategic buyers and users the editing and approval of the orders, but brought temporary challenges in terms of cooperation and organization of the process, which were eventually stabilizied in the last year described.

In the beginning of the implementation process of Ebuy (Coupa) I established two hypotheses:

H1: The implementation of Ebuy Coupa will bring more regulations and conflicts between buyers and procurement agents due to changes of the digitalized system.

H2: The personnel costs will decrease through introducing part timers or decreasing over hours payments due to more catalogues and catalogue products, as well as through the responsability of users to edit their purchase requisitions.

\section{FINDINGS AND ANALYSIS}

Genpact ensures the procurement process for several companies, which outsource the procurement function and give instructions to Genpact regarding the standards of performing procurement and measuring and evaluating the procurement process and its efficiency. Two systems for processing purchase requisitions of customers were mainly done through Ariba and starting with 2016 with Ebuy (Coupa). Procurement agents were responsible for analyzing the received purchase orders, correcting them or asking all the necessary information such as offers from suppliers, price negotiations, delivery dates and terms clarification and other and inserting them in the purchase order, as shown in Figure 3.

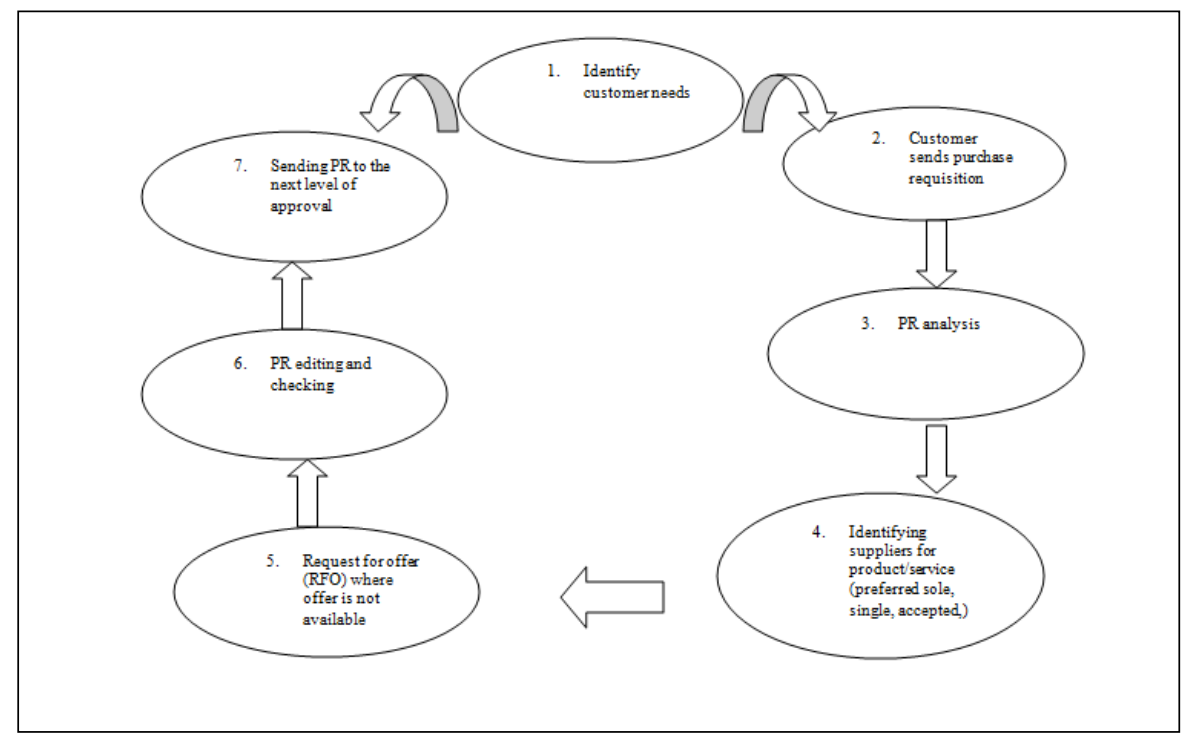

Figure 3. Procurement processing at Genpact

Source: Author's own research 
After the purchase requisitions are checked, corrected and approved the purchase orders are released and sent further to other levels of approval, such as for budget and document verification to buyers. Buyers had higher levels of approvals, meaning they were already on a strategic level of procurement. Then POs are sent to the vendor, who has to accept the PO. If the vendor accepts the PO this implies the creation of a binding contract. Based on this contract products will be delivered from the vendor to the user of the product, who can notify the procurement agent in case the delivered products have flaws or in case the products number is incorrect. The procurement is also responsible for the three way matching, respectively of the purchase request, PO and invoice. After the three way matching if there are no differences the PO is closed. Otherwise, if there are discrepancies the purchase agents have to clearify them before they can be closed.

The general principle of the procurement processing was followed in the case of all software used for this field of activity. However the change from Ariba system to Ebuy (Coupa) had simplified in some ways the procurement processing for the procurement personnel of the company.

One of the main differences of working with Ebuy in comparison to Ariba is the reduced need for involving SAP operations, such as for example in the case of cancelling orders or changing purchase orders or goods receipts. In Ebuy these operations are done directly on the platform and there is no need for an SAP connection of the system, while in Ariba more of these activities could be done only in SAP. The reduced dependency to SAP also decreased the processing time for purchasing agents, who did not need to access more systems at once.

The implementation of the new system, Ebuy (Coupa) also brought more advantages as the possibility of working on higher volumes of purchase requests due to some changes in the system and policy of the company, such as the obligation of users to fill in all the fields of the purchase requistion, as shown in Table 1 . This has also decreased the processing time of several PRs for the procurement agents.

Table 1. Advantages and challenges of the organizational and procurement process change management by going from Ariba to Ebuy (Coupa) for Genpact between 2016-2019

\begin{tabular}{|c|c|}
\hline Advantages & Challenges \\
\hline $\begin{array}{l}\text { - Changing POs, cancelling POs and cancelling } \\
\text { GRs directly in Ebuy. (no SAP needed) }\end{array}$ & $\begin{array}{l}\text { - Conflicts between users and procurement agents } \\
\text { and/or buyers. }\end{array}$ \\
\hline  & $\begin{array}{l}\text { - High volumes of PRs per procurement agent in } \\
\text { some periods. }\end{array}$ \\
\hline $\begin{array}{l}\text { - Procurement agents and buyers division of work } \\
\text { for different amount approvals made it possible } \\
\text { for procurement agents to process higher } \\
\text { volumes. }\end{array}$ & $\begin{array}{l}\text { - Need of more strict personnel organization with } \\
\text { holidays and free days in order to cover high } \\
\text { volumes of PRs. }\end{array}$ \\
\hline $\begin{array}{l}\text { - More catalogues and catalogue products where } \\
\text { users can order without any processing needed } \\
\text { from procurement agents and/or buyers. }\end{array}$ & $\begin{array}{l}\text { - More process changes from buyers regarding } \\
\text { levels of approvals, preferred suppliers, } \\
\text { communication with users and vendors, etc. }\end{array}$ \\
\hline $\begin{array}{l}\text { - More contact between users, procurement agents } \\
\text { and buyers. }\end{array}$ & \\
\hline $\begin{array}{ll}\text { - } & \text { Decreased personnel costs. (also part time work } \\
\text { was possible) }\end{array}$ & \\
\hline $\begin{array}{l}\text { - No need for checking the Ebuy system for PRs } \\
\text { throughout the day (as in Ariba) as procurement } \\
\text { agents receive by email or in Ebuy inbox all new } \\
\text { PRs. }\end{array}$ & \\
\hline
\end{tabular}

Source: Author's own research 
Another advantage of Ebuy (Coupa) was the creation of several catalogues, where users could order without any need of processing from the procurement personnel, which decreased waiting time for users to wait for procurement agents and buyers to edit and approve the purchase requisition. Such catalogue orders allow a direct, digitalized PO creation and dispatch to the vendor, who could also approve in the same system through their account, as shown in Figure 4.

Through the catalogue products were presented with image, description and users could order the number of products desired directly and the order would be sent to the vendor without processing from purchase agents. If there were discrepancies between the delivered products and the ordered products, the user would have to contact the vendor for the corrections without the involvement of the procurement agent. For catalogue orders the advantage would be also that procurement agents would not have responsability of these orders, as they did not process them. In the case of high conflicts with the vendor the users could ask for involvement of procurement agents and /or buyers, but only if vendors would not be cooperating as to correcting the error for the order.

The changes of such catalogue orders would be done also through the Ebuy system by the users directly without the need of accessing SAP. The users would get a training for using the system and would have to share responsability of order processing at least for catalogue orders.

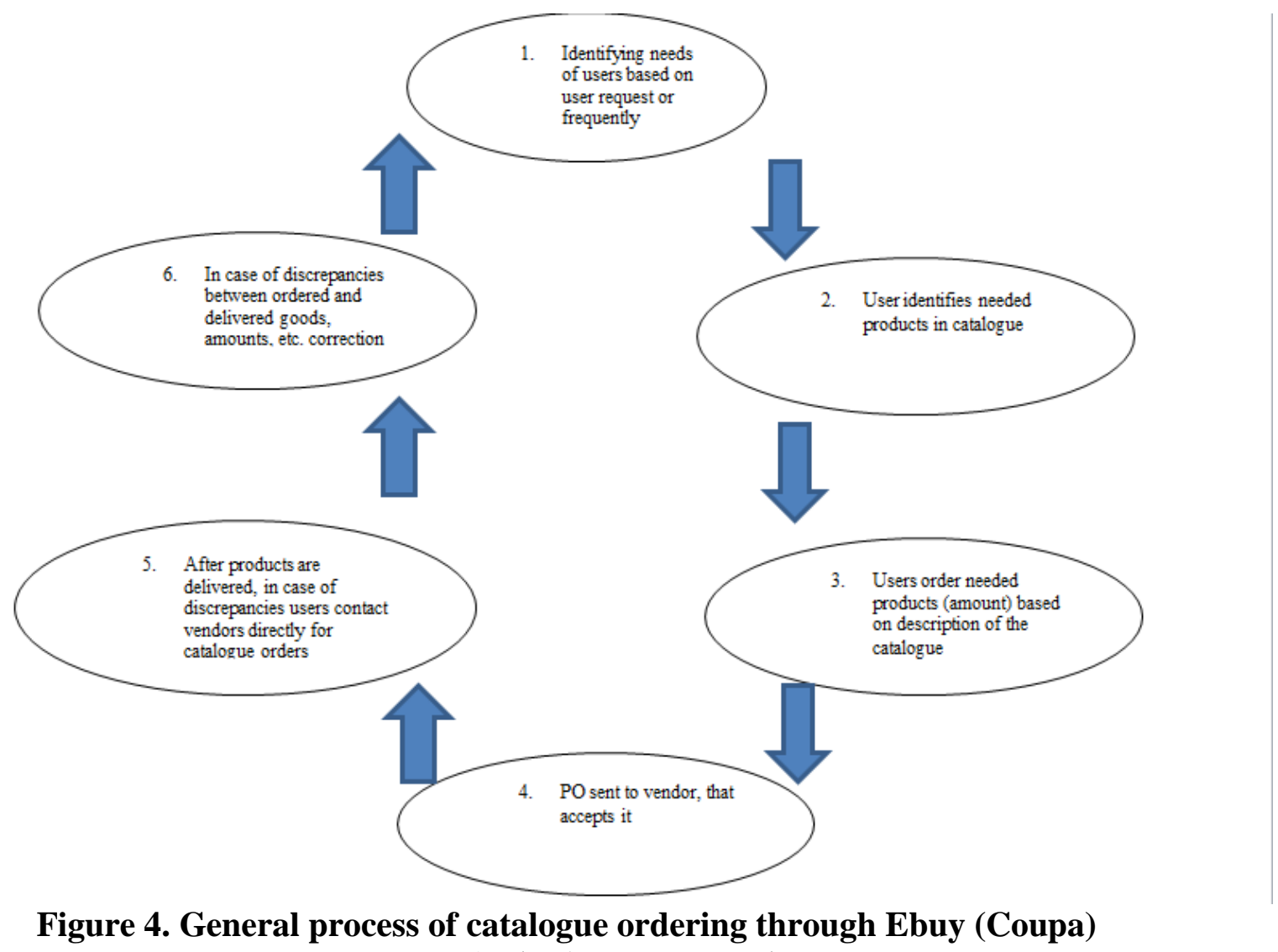

Source: Author's own research

The implementation of Ebuy also reduced personnel costs as no extra hours were needed from the procurement agents to process more orders or work on the same orders extra and also there was one more employee, who started to work part time instead of full time as by common agreement with the employers.

The implementation of Ebuy (Coupa) did not only mean more advantages, but also challenges. For example, there was more pressure on procurement agents from users and buyers to process orders very quickly after the purchase request was sent even though they were normally allowed a few 
days to process, which caused conflicts. Furthermore, it also brought a hig volume of purchase requests in some periods, which implied increased need of work volume per procurement agent. The rapid changes brought by buyers to the process in time also caused many times confusion for procurement agents and/or several processing errors, which also led many times to conflicts or time consumption for solving the issues. Another concern of the strategic buyers was the security of the sensitive data regarding offers, users' and buyers' data and company data and for this periodical trainings for employees were organized in order to inform which information is allowed to be sent electronically, formulation of messages and other such data.

In Ariba, on the other side, users could actually send the orders without all filled in details of the order, such as product description, delivery terms and date, amount, supplier and other such data and this meant more time spent by the procurement agent to search for the necessary information either by contacting the user, the regulations or the supplier/s. Furthermore, for several processes, such as cancelling orders or changing data for orders the SAP was necessary, which involved also more training and the accessing of two systems at once for different operations. Procurement agents would also not be informed by email about the necessary processing of purchase requisitions and could only access them in the system. Another issue of the system would be the need for periodical check up of the purchase requisitions status throughout a day as otherwise more purchase requisitions would not be solved on time, namely within the turnaround time (TAT), which would imply less good results from the perspective of the strategic procurement and the possibility of cancelling the contract with Genpact or reducing the payment.

\section{CONCLUSIONS}

As a conclusion the implementation of Ebuy (Coupa) software instead of Ariba brought numerous simplifications of the procurement process, however with numerous challenges regarding the personnel conflicts especially between procurement agents and strategic buyers, which confirmed the first hypothesis. The second hypothesis that the personnel costs will decrease through introducing part timers or decreasing payments due to more catalogues and catalogue products, as well as through the responsability of users to edit their purchase requisitions was partly confirmed. This is because the number of part timers increased by only 1 person for the whole team, but the decreasing of extra hours to process PRs and thus of their payment was confirmed.

Thus, e-procurement technology has also contributed to a more dynamic processing of orders and establishing a network between end customers, strategic buyers and purchasing agents at Genpact, however it also brought challenges such as periodical conflicts, especially between straegic buyers and purchasing agents due to dynamic changes of regulations. This was solved in time as the process changes became the new internal rules of the procurement department.

E-procurement systems are now a trend within large companies especially as the globalization and internationalization process of companies are becoming more and more dominant.

In terms of strategic procurement this field is also a significant one, as the need for ensuring cost efficient contracts with suppliers, as well as favourable conditions for both the company procuring and for end customers are key elements for the success of this field. In the next years it is expected that procurement will be a main function for all organizations and its digitalization will bring numerous changes in terms of organization and process.

A main objective for future research is to study the impact of e-procurement on the hierarchical levels of the companies, processes, change and personnel management of the organizations. 


\section{REFERENCES}

Buzzetto, R. R., Bauli, M. R. \& de Carvalho, M. M. (2020). The key aspects of procurement in project management: investigating the effects of selection criteria, supplier integration and dynamics of acquisitions. Production, 30, 1-18.

Cârstea, G., Păun, O. \& Păun, S. (2014). Quality management in procurement and management of material resources. Paper presented at the $7^{\text {th }}$ International Management Conference 'New Management for the New Economy. Bucharest, Romania.

Hila, C. M. \& Dumitrașcu, O. (2014). Outsourcing within a supply chain management framework. Paper presented at the $8^{\text {th }}$ International Management Conference. Bucharest, Romania.

Lederer, A. L., Mirchandani, D. A. \& Sims, K. (2001). The search for strategic advantage from the world wide web. International Journal of Electronic Commerce, 5(4), 117-133.

Mahdillou, H. \& Akbari, J. (2014). E-procurement adoption, its benefits and costs. Academic Literature Review, 1-56.

Morris A., Stahl, A., Herbert, R. (2000). E-Procurement: streamlining processes to maximize effectiveness. Houston, TX: Luminant Worldwide Corporation USA.

Piera, C., Roberto, C., Giuseppe, C. \& Teresa, M. (2014). E-procurement and E-supply chain: Features and Development of E-collaboration. IERI Procedia, 6, 8-14.

Procurement. (n.d.). In Coupa. Retrieved February 10, 2020, from https://www.coupa.com/products/procurement/

Presutti Jr, W. D. (2003). Supply management and e-procurement: creating value added in the supply chain. Industrial Marketing Management, 32(3), 219-226.

Ravi, K. (2012). Spend BI and Analytics. Retrieved February 1, 2020, from https://practicalanalytics.wordpress.com/2012/03/08/spend-bi-and-analytics/

Sabri, E. (2019). Technology optimization and change management for successful digital supply chains. Hershey, PA: IGI Global.

Sitar, C. P. (2011). E-procurement: the future of purchasing management. International Conference Modern Approaches in Organisational Management and Economy, 5(1), 542-546.

Van Weele A. (1994). Purchasing Management: Analysis, Planning and Practice. London, UK: Chapman \& Hall. 